\title{
Original article (short paper) \\ Electromyographic assessment of trunk and shoulder muscles during a Pilates pull-up exercise
}

\author{
Isabel C.N. Sacco \\ Eduardo T.T. Mori \\ Bergson C. Queiroz \\ University of São Paulo, Brazil \\ Nadia Marconi \\ University of Brasilia, Brazil \\ Ivye L. R. Pereira \\ University of São Paulo, Brazil
}

\begin{abstract}
This study compares surface electromyographic activity of the internal oblique, rectus abdominis, multifidus, iliocostalis, anterior deltoids during the pull-up on a lower and on a higher difficulty level. We assessed nine adults with previous experience in Pilates. The root mean square (RMS) values were normalized by maximum isometric contraction for each participant. During the ascent phase, the low spring position showed a significantly higher RMS than the high spring position of $8.9 \%$ for deltoid, $17.2 \%$ for internal oblique, $22.3 \%$ for rectus abdominis, $4.1 \%$ for iliocostalis, and $5.6 \%$ for multifidus, and in the descent phase, the RMS in the lower spring exceeded significantly the high spring position in $1.6 \%$ for the deltoid, $10 \%$ for internal oblique, $31.4 \%$ for rectus abdominis and $11.4 \%$ for iliocostalis. There was no predominance of abdominal muscles over the shoulder muscle in any spring position. The pull-up exercise can be a useful choice for the core and anterior deltoid muscles strengthening.
\end{abstract}

Keywords: biomechanics, electromyography, exercise therapy, abdominal wall

Resumo - “Avaliação eletromiográfica de músculos do tronco e do ombro durante um exercício Pilates de pull-up." Este estudo compara a atividade eletromiográfica de superfície dos músculos oblíquo interno, reto abdominal, multífidos, iliocostal e deltóide anterior durante o pull-up em dois níveis de dificuldade (mola alta e mola baixa). Foram avaliadas nove adultos com experiência anterior em Pilates. Os valores RMS foram normalizados pela contração isométrica máxima. Durante a fase de subida, a posição de mola baixa mostrou RMS significativamente maiores em relação a alta de $8,9 \%$ para deltóide, $17,2 \%$ para o oblíquo interno, $22,3 \%$ para o reto abdominal, 4,1\% para iliocostal, e 5,6\% para o multífido, e na fase de descida, em 1,6\% para o deltóide, $10 \%$ para oblíquo interno, $31,4 \%$ para o reto abdominal e $11,4 \%$ para o iliocostal. Não houve predomínio dos músculos abdominais sob o músculo do ombro em qualquer posição de mola. $\mathrm{O}$ exercício de pull-up pode ser ferramenta útil para o fortalecimento da musculatura do core e do músculo deltóide anterior.

Palavras-chave: biomecânica, eletromiografia, terapia por exercício e parede abdominal

Resumen - "Evaluación electromiográfica de los músculos del tronco y del hombro durante un ejercicio Pilates de pull-up." Este estudio compara la EMG superficial de los músculos recto del abdomen, oblicuo interno, multifidos, ilio-costal y deltoides anterior durante el ejercicio pull-up en dos niveles de dificultad. Se evaluaron a nueve adultos experimentados en Pilates. Los valores de RMS se normalizaron por la contracción isométrica máxima. Durante la fase de ascenso, la posición baja del resorte mostró valores significativamente majores de RMS que la posición alta de $8,9 \%$ para lo deltoides, $17,2 \%$ para oblicuo interno, $22,3 \%$ para recto abdominal, $4,1 \%$ para ilio-costalis, y $5,6 \%$ para multifidos. En la fase de descenso, el RMS, en el muelle inferior, excede significativamente la posición alta del resorte en $1,6 \%$ para el deltoides, $10 \%$ para oblicuo interno, $31,4 \%$ para recto abdominal y $11,4 \%$ para ilio-costalis. No hubo predominio de los músculos abdominales bajo los deltoides anteriores. Pull-up puede ser una herramienta útil para el trabajo del core y para la fortificación del deltoides anterior.

Palabras clave: biomecánica, electromiografía, terapia de ejercicio, la pared abdominal 


\section{Introduction}

The Pilates method was created by Joseph Pilates and consists of stretching, strengthening, and proprioception exercises with the entire attention of practitioners focused on muscle control, posture, and breathing (Johnson, Larsen, Ozawa, Wilson, \& Kennedy, 2006; Muscolino \& Cipriani, 2004a; Stolze et al., 2012; Wells, Kolt, \& Bialocerkowski, 2012). The main focus of the method is on trunk musculature; therefore, it can be classified as a program of "core stabilization"(Amorim, Sousa, \& Santos, 2011; Akuthota \& Nadler, 2004; Barr, Griggs, \& Cadby, 2007; Stolze, Allison, $\&$ Childs, 2012). Pilates method has been considered as an important tool for rehabilitation and injury prevention (Anderson \& Spector, 2000, Lim, Poh, Low, \& Wong, 2012) and also has been the subject of recent trends in Brazilian scientific investigations (Bertolla, Baroni, Leal Junior, \& Oltramari, 2007; Queiroz et al., 2010; Rocha-e-Silva, 2009; Sacco et al., 2005).

Trunk flexion exercises, such as the pull-up, may compromise the ability of the lumbar extensor muscles to bear the shear forces on the lumbar column. Despite some evidences correlating these exercises with increased susceptibility to disc injury, it is possible to increase the spine stability and thereby reduce the risk of damage to the structures of the column, by controlling the strength of the abdominal and back extensors muscles (Brown \& McGill, 2008). In one more physiological sense the "Pilates" core stabilization" is related to coordinated and simultaneous activation of the trunk and hip muscles, which is associated to reduction the risk of disc injury (Lim et al., 2012; Van Dieen, Cholewicki, \& Radebold, 2003; Wong, Leong, Chan, Luk, \& Lu, 2004).

For this reason, the Pilates' pull-up exercise could be considered as a good therapeutic and fitness option when the main goal is workout abdominal, back extensors muscles, and shoulder muscles in a closed-kinetic chain in opposition to the elastic loads attached to the chair equipment. During the exercise performance, the practitioner also has the challenge to control shoulder and trunk muscles simultaneous and dynamically (Akuthota \& Nadler, 2004; Isacowitz, 2006; Pilates, 2000). Despite being recommended for shoulder girdle muscles strengthening (Isacowitz, 2006), the main focus of the pull-up exercise is to strengthen the core that comprises the coordinated and simultaneous activation of the trunk and hip muscles, and which is one of the fundamental concepts of Pilates (Gallagher \& Kryzanoswska, 2000a; Muscolino \& Cipriani, 2004b; Pilates, 2000). The main principle is the tightening of the muscular centre of the body or "powerhouse," located between the pelvic floor and the ribcage during exercises. Probably, this is one of the main reasons why Pilates is suitable to promote core stability, control and strength (Wells et al., 2012).

Because of its complexity, the pull-up exercise can be used in a final phase of sports rehabilitation and improvement of the performance of athletes and dancers. A biomechanical investigation of the pull-up exercise would lead to a better comprehension of its potential to strengthen the core and shoulder girdle muscles and to understand the relationship between the activation of trunk flexors and extensors muscles. Identification of muscles working patterns is a main concern among resear- chers and clinicians (Marques, Hallal, \& Gonçalves, 2012) and these deeper insights will allow us to discuss more properly the potential advantages and disadvantages of this exercise for the core stabilization and for the lumbar region, thereby contributing to the grounding both of rehabilitation and physical conditioning practices.

This study aimed to compare the surface electromyographic activity of the internal oblique, rectus abdominis, multifidus, iliocostalis, and anterior deltoid during the pull-up on two levels of difficulty, modified by the different anchoring positions of the springs. This study addressed the following hypotheses: (i) the different anchoring of spring positions would generate distinct patterns of trunk and shoulder muscles activation, (ii) the trunk muscles would activate predominantly over shoulder muscles, regardless of the level of exercise difficulty and phase of movement, (iii) among the trunk muscles there would be a predominant activity of flexors muscles, particularly the internal oblique, over the extensors muscles regardless of the level of exercise difficulty and phase of movement.

\section{Methods}

\section{Experimental approach to the problem}

The present study characterized the EMG activity of anterior trunk muscles (internal oblique and rectus abdominis), posterior trunk muscle (multifidus and iliocostalis) and a shoulder girdle muscle (anterior deltoid) during the pull-up exercise performed in two difficulty levels of difficulty by nine experienced healthy adults. Within-muscle EMG comparison were made to evaluate the existence of co-contraction (trunk flexor and extensor) and the importance of trunk and shoulder muscle activation according to the phase of the exercise (ascent or descent phase). The spring anchoring change might bring important variation in the intensity of exercise inferred from EMG activity.

\section{Participants}

Nine healthy adults ( 5 men and 4 women, $28 \pm 5$ years; 1.72 $\pm 0.07 \mathrm{~m} ; 68 \pm 12 \mathrm{~kg}$ ) volunteered for this study. All assessed individuals had previous Pilates training (at least 6 months, 2 times a week, 48 sessions minimum). Participants were excluded from the study if they had a history of recent (in the last two years, with a duration of seven days) lower back pain, musculoskeletal or neuromuscular injury, previous abdominal surgeries, scoliosis, important lower limbs asymmetry, or postural deviations.

All procedures were approved by the Local Ethics Committee (protocol no. 079/10), and the participants gave their written informed consent.

\section{Task}

During the pull-up the volunteers were instructed to perform a flexion (upward phase) and an extension (downward) of the trunk segments using the Pilates' chair in opposition to a spring load. During the initial position, the hands were kept on top of 
the equipment with wrists in extension while upper limbs; trunk and hips were in flexion (Figure 1). During the upward phase, the volunteer lifted the body weight upwards moving the shoulders in extension and the trunk segments and hip in flexion while the lower limbs are extended with the feet in contact with the pedal. In the upward phase, springs progressively reduce their lengths. The opposite combination of movements is observed during the downward phase, while springs stretch. During both movement phases, the ankles are kept in plantar flexion. The force provided by this pedal could be modulated by the number, the strength, and the positioning of the springs (Isacowitz, 2006; Queiroz et al., 2010; Gallagher \& Kryzanowska, 2000b).

The pull-up exercise was performed in two levels of difficulty (high and low springs) in a random order (by simple drawing) for each participant, in four series of three cycles, with a oneminute interval to rest. This approach provided a total of 12 cycles in each level of difficulty for analysis. The performance speed was controlled by verbal commands during the upward and downward movements of the lower limbs, following the cadence marked by a digital metronome to $100 \mathrm{bpm}$. All participants were experts in the Pilates method and experienced in responding to verbal rhythmic commands.

\section{Procedures}

During the pull-up exercise, the electromyographic signal of four muscles (internal oblique, rectus abdominis, iliocostalis, multifidus) in the trunk and one in the arm (anterior deltoid), were unilaterally recorded on the right side of the body. This exercise started with the participant in the position 1 (as shown in Figure 1), with lower limbs extended and feet touching the equipment's pedal. The pedals were connected to springs that were used in different positions classified as low and high. The trunk was in flexion; the pelvis was retroverted and the hands were holding the top of the chair.

The exercise was performed by raising the body using the strength of the abdominals and upper limbs with an increase in the flexion of the trunk segment (Figure 1). Two springs provided assistant force on the pedal to raise the body. This force was modulated by changing the chair's spring position in order to modify the exercise's demand.

The elastic constant $(\mathrm{k})$ of each spring has been found as $280 \mathrm{~N} / \mathrm{m}$. At the beginning of the movement, the spring, which was fixed in the high position, at $35^{\circ}$ from the horizontal plan, provided a vertical support of $209 \mathrm{~N}$ and in the low spring position, at $25^{\circ}$ from the horizontal plan, provided a support of $150 \mathrm{~N}$ (Figure 1).

An 8-channel EMG system (DE 2.2L Bagnoli model; Delsys, Boston, MA, EUA) was used to measure electromyography (EMG). Ag/AgCl bipolar electrodes $(10 \mathrm{~mm})$ were placed over each muscle with an interelectrode distance of $20 \mathrm{~mm}$ center to the center. EMG signals were sampled at $1 \mathrm{kHz}$ and amplified 2000 times; the common mode rejection ratio was $92 \mathrm{~dB}$ (at $60 / 10 \mathrm{~Hz}$ ) and the input impedance of the system was $10^{15} \Omega$. After skin preparation, which consisted of shaving and cleaning with rubbing alcohol and gauze, the electrodes were fixed with transpore $^{\circledR}(3 \mathrm{M})$ adhesive tape on the right side of the body.

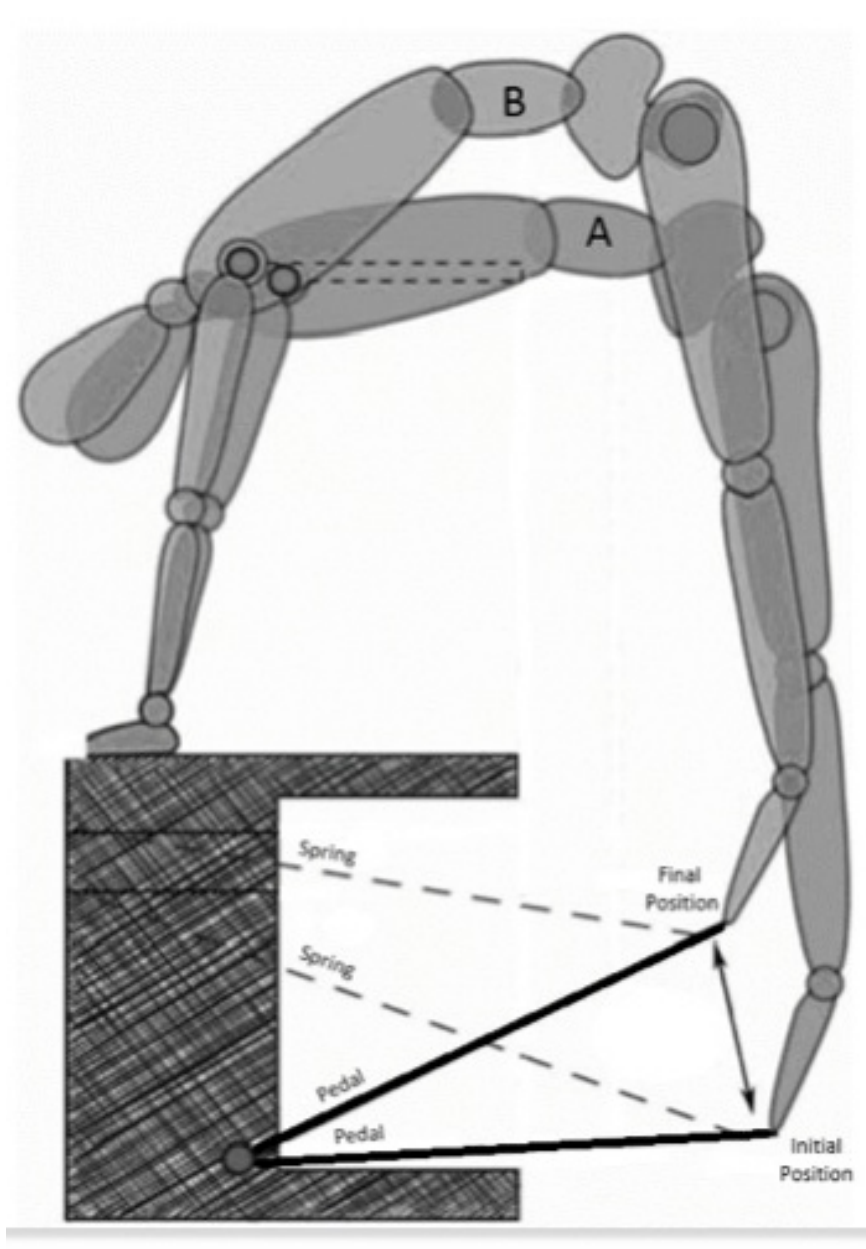

Figure 1. The experimental set-up. The chair equipment used by the participants to perform the pull-up is represented in black. The task was performed with the participant's hands in contact with the chair's top (palmar contact) and toes in contact to the equipment's pedal (maximum plantar-flexion). In the initial position, wrist and elbow joints were extended while head and shoulder joints were flexed, trunk, hips and, ankle joints were in flexion while knee joints were extended. In the initial position, the pedal was parallel to the floor. In the final position, the pedal elevates, as shown. The end of spring (dashed line) was attached to the back of chair while another ending to the pedal. The highest and lowest springs formed a $25^{\circ}$ and $35^{\circ}$ angle, respectively, related to the floor.

The placement of electrodes on the iliocostalis, multifidus and anterior deltoid muscles followed the recommendations of the project Surface EMG for a non-invasive assessment of muscles (SENIAM, 2005). For the rectus abdominis, we followed the recommendations of Grenier and McGill (Grenier \& McGill, 2007), and for the internal oblique, we followed Escamilla, McTaggart, Fricklas, and DeWit (2006). A reference electrode was placed over the right clavicle.

For normalization purposes, before the performance of the exercises, four seconds of electromyographic data were recorded for each muscle while the participants performed maximum voluntary isometric contractions (MVIC) against manual resistance. The highest mean value during $500 \mathrm{~ms}$ from the two central seconds' window from two trials of each muscle was chosen as the representative MVIC. For testing the MVICs of the iliocostalis and lumbar multifidus muscles, 
trunk extension was performed in a prone position, with the lower limbs restrained and maximum resistance applied to the upper back (SENIAM, 2005). For testing the MVIC of the rectus abdominis muscles, the upper trunk was maximally flexed with maximum resistance applied to the shoulders in the trunk extension direction with knees flexed $90^{\circ}$ and feet restrained (Escamilla et al., 2006). For testing the MVIC of the internal oblique muscles, the trunk was maximally flexed and rotated to the left and to the right side with maximum resistance at the shoulders in the opposite direction of rotation in a supine position with knees flexed $90^{\circ}$ and feet restrained (Escamilla et al., 2006). And for testing the MVIC of the anterior deltoid muscles, the participant was sitting with the shoulder abduction in slight flexion, arms hanging vertically and the palm pointing inwards. The maximum resistance applied against the antero-medial surface of the arm in the direction of adduction and slight extension (SENIAM, 2005).

Tracking data from the right greater trochanter was used to synchronize the phases (upward and downward) of the Pull-up cycles. An Optotrak Motion Analysis System - OPTOTRAK 3020 (Northern Digital, Waterloo, Ontario, Canada) sampled at $100 \mathrm{~Hz}$ the LEDs (light emitting diodes) fixed at the right greater trochanter. All EMG data were sampled at $1 \mathrm{kHz}$ using the Optotrak software and a synchronization unit (ODAUII) with a 12-bit acquisition board.

\section{Data processing}

After the offset removal from the raw EMG - if existent, the signal was digitally zero lag bandpass filtered (Butterworth, $2^{\text {nd }}$ order $10-400 \mathrm{~Hz}$ ) and normalized by the MIVC EMG signal.
Each movement phase (upward and downward), determined by kinematic data of the trochanter, was represented by its average root mean square (RMS) of the whole phase duration. The average RMS of 12 cycles (12 ascent phases and 12 descent phases) was calculated for each muscle and spring.

\section{Statistical analyses}

The mean values of the normalized muscles activities were compared between the two phases (ascent x descent) in each spring position and between spring positions within each movement phase by two-sided paired $t$-tests. The five muscles were compared at each movement phase and spring position by ANOVAs for repeated measures followed by Newman-Keuls post-hoc tests. We adopted an alpha error of 0.05 and statistics were performed using Statistica software (v.7 StatSoft, Inc.). Given the sample size evaluated, an alpha of 5\%, a moderate effect size $(f=0.45)$, the statistical power was 0.852 for the $F$ test used.

\section{Results}

The percentage differences presented refer to the ratio of the highest value obtained by the absolute difference between the values.

\section{Comparisons between springs}

In the ascent phase, the EMG activity observed in the low spring position (150 N assistance force) significantly outper-

Table 1. Mean ( \pm standard deviation) values of normalized RMS (by the maximal voluntary contraction - MVIC) of the muscles evaluated, $p$ values of comparisons between the phases of the movement (ascent $\mathrm{x}$ descent) and between spring positions (high $\mathrm{x}$ low), and $\mathrm{p}$ values of comparisons among muscles in each phase and spring.

\begin{tabular}{ccccc}
\hline Muscle & Spring position & Ascent phase & Descent phase & $p^{1}$ \\
\hline Internal Oblique & High & $72 \pm 34$ & $63 \pm 31$ & 0.012 \\
$(\%$ MVIC) & Low & $87 \pm 35$ & $70 \pm 31$ & $<0.001$ \\
& $p^{1}$ & $p<0.001$ & $p<0.001$ & \\
\hline \multirow{2}{*}{$\begin{array}{c}\text { Rectus Abdominis } \\
\text { (\% MVIC) }\end{array}$} & High & $66 \pm 26$ & $48 \pm 18$ & $<0.001$ \\
& $p^{1}$ & $85 \pm 40$ & $70 \pm 33$ & $<0.001$ \\
\hline Multifidus & High & $p<0.001$ & $p<0.001$ & \\
(\% MVIC) & Low & $67 \pm 31$ & $69 \pm 31$ & 0.37 \\
& $p^{1}$ & $p<0.001$ & $69 \pm 36$ & 0.045 \\
\hline Iliocostalis & High & $46 \pm 31$ & $p=0.141$ & $<0.001$ \\
$(\%$ MVIC) & Low & $48 \pm 33$ & $44 \pm 29$ & 0.09 \\
& $p^{1}$ & $p<0.001$ & $p<0.001$ & \\
\hline Anterior Deltoid & High & $61 \pm 36$ & $59 \pm 34$ & 0.082 \\
$(\%$ MVIC) & Low & $67 \pm 28$ & $60 \pm 21$ & 0.017 \\
\hline$p^{2}$ High Spring & $p^{1}$ & $p<0.001$ & $p<0.001$ & $p<0.001$ \\
\hline$p^{2}$ Low Spring & & $p<0.001$ & $p<0.001$ &
\end{tabular}

$p^{1}$ two-sided paired t test, $p^{2}$ ANOVA for repeated measures 
formed the high spring position (assistance force of $209 \mathrm{~N}$ ) in $8.9 \%$ for anterior deltoid $(p<0.001), 17.2 \%$ for internal oblique $(p<0.001), 22.3 \%$ for rectus abdominis $(p<0.001), 4.1 \%$ for iliocostalis $(p<0.001)$ and $5.6 \%$ for multifidus muscles $(p<0.001)$. In the descent phase, the EMG signals observed in the lower spring exceeded significantly the EMG values observed in the high spring position in $1.6 \%$ for the anterior deltoid $(p<0.001)$, $10 \%$ for internal oblique $(p<0.001), 31.4 \%$ for rectus abdominis $(p<0.001)$ and $11.4 \%$ for iliocostalis muscle $(p<0.001)$, but not for the multifidus.

\section{Comparison among muscles}

In the high spring position, during the ascent phase, the internal oblique muscle showed a $6.9 \%$ higher activity compared to the multifidus muscle ( $p=0.004$ ), while the multifidus muscle showed an $8.9 \%$ greater activity $(p=0.002)$ compared to the anterior deltoid, and $31.3 \%$ greater $(p=0.009)$ than the iliocostalis muscle. For the descent phase, in the high spring position, the multifidus showed an $8.7 \%$ higher activity $(p=0.026)$ than the internal oblique, and $14.5 \%$ higher $(p<0.001)$ than the anterior deltoid muscle. The anterior deltoid was more active in $18.6 \%$ $(p=0.003)$ than the rectus abdominis, and in $33.8 \%(p=0.004)$ than the iliocostalis muscle.

In the low spring position, the muscles differ from each other only during the descent phase. The multifidus presented a $13 \%$ higher activity $(p=0.048)$ than the anterior deltoid.

\section{Comparison between phases of movement (ascent and descent)}

In the high spring position, the internal oblique $(12.5 \%$, $p=0.012)$, rectus abdominis $(27.3 \%, p=<0.001)$, and iliocostalis $(15.2 \%, p=<0.001)$ muscles showed significantly greater electrical activity in the ascent phase over the descent phase. In the low spring position, the internal oblique $(19.5 \%, p=<0.001)$, rectus abdominis (17.6\%, $p=<0.001)$, multifidus $(2.8 \%, p=0.045)$ and anterior deltoid $(10.4 \%, p=0.017)$ muscles showed significantly greater electrical activity in the ascent phase over the descent phase.

\section{Discussion}

The general results allowed us to confirm the first hypothesis whether the different anchoring of spring positions would generate distinct patterns of trunk and shoulder muscles activation, since we observed distinct levels of muscle activity for each level of spring anchoring.

In the ascent phase with the low spring position, which provided less assistance (150 $\mathrm{N}$ on the starting position), we observed greater EMG activity of all assessed muscles compared to the high spring position, and in the descent phase, anterior deltoid, internal oblique, and rectus abdominis and iliocostalis showed greater activation compared to the high spring position. However, the results not completely confirmed the second hypothesis that the trunk muscles would activate predominantly over shoulder muscles since the anterior deltoid showed higher activity than rectus abdominis and iliocostalis in the descent phase on the high spring position. Furthermore, during the ascent phase on the low spring position, no significant difference between trunk and shoulder muscles was identified. In the third hypothesis, there were no predominance activity of flexors muscles over the extensors muscles as was assumed, since in the ascent phase on the high spring position, there was an increase in the internal oblique activity over multifidus, but in the descent phase on the high spring position, there was an increase in the multifidus activity over internal oblique. In the ascent phase on the high spring position, there was also an increase in the multifidus muscle over anterior deltoid and the iliocostalis muscle. However, in the descent phase on the high spring position, the anterior deltoid showed higher activity than rectus abdominis and iliocostalis, as we said, despite showing less activity than multifidus. In the descent phase in the low spring position, multifidus showed higher activity compared to the anterior deltoid.

In the comparisons between the ascent and descent phases for each muscle, in the high spring position in the ascent phase, we observed higher RMS values, with significantly difference, for the internal oblique, rectus abdominis and iliocostalis. In contrast, in the low spring position in the ascent phase, the internal oblique, rectus abdominis, multifidus and anterior deltoid muscles showed higher EMG values.

We can suggest by the comparisons among the trunk flexors muscles that internal oblique and rectus abdominis are equally important for the trunk flexion in this exercise in spite of the level of difficulty. However, the higher activation of the internal oblique for both spring positions and movement phases indicates the crucial importance of this muscle to maintain the pelvis retroversion while the trunk is flexed, as Queiroz et al. (2010) pointed out in other Pilates exercises; while the rectus abdominis acts, beyond the function of the trunk flexor, as an anchor for the internal oblique action, as also proposed by McGill et al. (1996).

During the pull-up exercise, the trunk flexion and the pelvic retroversion modifies the lever arms, considering the shoulder joint as the axis, the in two ways: [1] the center of body mass gets near the pull-up main movement axis in the shoulder, decreasing the resistance arm to the shoulder and [2] this forward movement of the center of mass also decreases the resistance arm to the pedal axis, increasing the ratio between the force arm (pedal axis - pedal extremity where the foot rests) and resistance $\mathrm{arm}$. The resultant internal forces, in addition to the spring assistance force, allow the body to go up. In this case, it is possible to propose the importance of the trunk flexor muscles (internal oblique and rectus abdominis) to bring forward the center of mass in the ascent phase for the high spring position. For the low spring position, where less assistance is provided, one may need the additional action of the anterior deltoid to modify the lever arm, besides the trunk muscles support.

The multifidus muscle showed the highest activity $(67 \%$ MVIC) compared to the other extensor assessed (iliocostalis $46 \%$ MVIC) in the ascent phase in the high spring position. McGill, Hughson, and Parks (2000) identified that lumbar flexion compromises the ability of the force generation of the 
iliocostalis muscle due to the obliquity of its fibers. This mechanical disadvantage may reduce the ability of this muscle to control intervertebral anterior shear forces while the multifidus function would be less affected by lumbar flexion. Therefore, the higher activity of the multifidus could reflect its pivotal role in lumbar vertebrae positioning and in controlling the intervertebral forces. This key role inferred by our EMG results is also consistent with the description that Wilke, Wolf, Claes, Arand, and Wiesend (1995) and Bojadsen, Silva, Rodrigues, and Amadio (2000) made in their studies, highlighting the role of the multifidus as the major lumbar extensor and stabilizer. However, even in exercises that require no trunk flexion and are performed isometrically (Holding test), there was a predominant action of the multifidus muscle (78\% MVIC) compared to the iliocostalis (65\% MVIC) (Ng, Richardson, \& Jull, 1997). Moreover, in the descent phase with the high spring position, the activity of multifidus overcomes the internal oblique, which was the most active muscle in the ascent phase among the five assessed muscles, suggesting that the multifidus muscle plays not only an important role in the spinal stabilization but also in the eccentric trunk control.

According to Granata and Marras (2000) and Kavcic, Grenier, and McGill (2004b), the co-contraction of both flexors and extensors muscles during the trunk flexion increases the spine's capability to support critical overloads and increase trunk stability; however, it increases the compression forces in the lumbar spine. The study of co-contraction in several patterns of exercises can guide the planning of training and rehabilitation activities (Marques, Hallal, \& Gonçalves, 2012). In the pull-up exercise, we observed values of MVIC between $48 \%$ (rectus abdominis) and $87 \%$ (internal oblique) for the flexor muscles, and values between $39 \%$ (iliocostalis) and $71 \%$ (multifidus) for the extensor muscles. Kavcic et al. (2004b) have found that values of MVIC around 57\% for internal oblique, $46 \%$ for rectus abdominis and $25 \%$ for multifidus, provided enough co-contractions for stabilization purposes. All these findings together with our results suggest that the activity magnitude between flexors and extensors in the pull-up exercise can provide sufficient spine stability when used in training practice. However, it is important to take into consideration the probable increase in the lumbar spine loads (Kavcic et al., 2004b) not only due to the exercise itself, but due to the position of trunk flexion, which has been suggested as a main factor for intervertebral disc herniation (Callaghan $\&$ McGill, 2001). Therefore, one should be careful to indicate this exercise in cases of lumbar dysfunctions.

Since the multifidus, internal oblique, rectus abdominis, and anterior deltoid muscles generated EMG activities generally above $60 \%$ of MVIC, we suggest that the pull-up exercise is an effective option for strengthening purposes(Anderson \& Spector, 2000), with either the high or low spring positions. Our results confirm the pull-up effectiveness as a tool for strengthening the core muscles, as stated by Kryzanowska and Gallagher (2000a) and Isacowitz (2006). The iliocostalis showed values between $39 \%$ and $48 \%$ MVIC, these activation magnitudes are sufficient to gain strength, which for Ekstrom et al. (2007) is at least $45 \%$ of MVIC.

\section{Practical applications}

The pull-up exercise is effective as an exercise for strengthening and conditioning all "power house" muscles, and the anterior deltoid plays an important role in controlling eccentrically the lowering of the body in the descent phase. The practitioner of this exercise must have a previous appropriate physical preparation for its performance since it demands high muscle activation to perform it while stabilize the lumbar spine. In order to progressively enhance the load and the level of muscular activity, it is highly recommended to change the anchoring position of the springs. The low spring position homogenizes and increases muscle activity, especially the trunk muscles.

\section{References}

Akuthota, V., \& Nadler, S. F. (2004). Core strengthening. Archives of Physical Medicine and Rehabilitation,85(3 Suppl 1), S86-92.

Amorim, T. P., Sousa, F. M., Santos, \& Rodrigues, J.A. dos. (2011). Influence of Pilates training on muscular strength and flexibility in dancers. Motriz: Revista de Educação Física, 17, 660-666.

Anderson, B. D., \& Spector, A. (2000). Introduction to Pilates-based rehabilitation. Orthopaedic Physical Therapy Clinics of North America, 9(3), 395-410.

Barr, K. P., Griggs, M., \& Cadby, T. (2007). Lumbar stabilization: a review of core concepts and current literature, part 2. American Journal of Physical Medicine \& Rehabilitation, 86(1), 72-80.

Bertolla, F., Baroni, B.M., Leal Junior, E.C.P., \& Oltramari, J.D. (2007). Effects of a training program using the Pilates method in flexibility of sub-20 indoor soccer athletes. Revista Brasileira de Medicina do Esporte, 13, 222-226.

Bojadsen, T. W., Silva, E. S., Rodrigues, A. J., \& Amadio, A. C. (2000). Comparative study of Mm. Multifidi in lumbar and thoracic spine. Journal of Electromyography and Kinesiology, 10(3), 143-149.

Brown, S. H., \& McGill, S. M. (2008). How the inherent stiffness of the in vivo human trunk varies with changing magnitudes of muscular activation. Clinical Biomechanics (Bristol, Avon), 23(1), 15-22.

Callaghan, J.P., \& McGill, S.M. (2001). Intervertebral disc herniation: studies on a porcine model exposed to highly repetitive flexion/ extension motion with compressive force. Clinical Biomechanics (Bristol, Avon), 16, 28-37.

Ekstrom, R. A., Donatelli, R. A., \& Carp, K. C. (2007). Electromyographic analysis of core trunk, hip, and thigh muscles during 9 rehabilitation exercises. Journal of Orthopaedic \& Sports Physical Therapy, 37(12), 754-762.

Escamilla, R. F., McTaggart, M. S., Fricklas, E. J., DeWitt, R., Kelleher, P., Taylor, M.K, . . \& Moorman, C.T. (2006). An electromyographic analysis of commercial and common abdominal exercises: implications for rehabilitation and training. Journal of Orthopaedic \& Sports Physical Therapy, 36(2), 45-57.

Gallagher, S. P., \& Kryzanoswska, R. (2000a). The Pilates method of body conditioning. Philadelphia: BainBridgeBooks.

Gallagher, S.P., \& Kryzanowska, R. (2000b). The complete writings of Joseph H Pilates. Philadelphia: BainBridgeBooks.

Granata, K. P., \& Marras, W. S. (2000). Cost-benefit of muscle cocontraction in protecting against spinal instability. Spine, 25(11), 1398-1404.

Grenier, S. G., \& McGill, S. M. (2007). Quantification of lumbar stability by using 2 different abdominal activation strategies. Archives of Physical Medicine and Rehabilitation, 88(1), 54-62.

Isacowitz, I. (2006). Pilates. Champaign, IL - Florida.

Johnson, E.G., Larsen, A., Ozawa, H., Wilson, C.A., \& Kennedy, K.L. 
(2006). The effects of Pilates-based exercise on dynamic balance in healthy adults. Journal of Bodywork and Movement Therapies, article in press.

Lim, E. C. W., Poh, R. L. C., Low, A. Y., \& Wong, W. P . (2012). Effects of pilates-based exercise on pain and disability in individuals with persistent nonspecific low back pain_a systematic review with meta-analysis. Journal of Orthopaedic \& Sports Physical Therapy, 41(2),70-80.

Kavcic, N., Grenier, S., \& McGill, S. M. (2004b). Quantifying tissue loads and spine stability while performing commonly prescribed low back stabilization exercises. Spine, 29(20), 2319-2329.

Marques, N.R., Hallal, C.Z., \& Gonçalves, M. (2012). Padrão de co-ativação dos músculos do tronco durante exercícios com haste oscilatória. Motriz: Revista de Educação Física, 18, 245-252.

McGill, S., Juker, D., \& Kropf, P. (1996). Appropriately placed surface EMG electrodes reflect deep muscle activity (psoas, quadratus lumborum, abdominal wall) in the lumbar spine. Journal of Biomechanics, 29(11), 1503-1507.

McGill, S. M., Hughson, R. L., \& Parks, K. (2000). Changes in lumbar lordosis modify the role of the extensor muscles. Clinical Biomechanics (Bristol, Avon), 15(10), 777-780.

Muscolino, J.E., \& Cipriani, S. (2004a). Pilates and the 'powerhouse' - I. Journal of Bodywork and Movement Therapies, 8, 15-24.

Muscolino, J.E., \& Cipriani, S. (2004b). Pilates and the "powerhouse' - II. Journal of Bodywork and Movement Therapies, 4(122-130).

Ng, J. K., Richardson, C. A., \& Jull, G. A. (1997). Electromyographic amplitude and frequency changes in the iliocostalis lumborum and multifidus muscles during a trunk holding test. Physical Therapy, 77(9), 954-961.

Pilates, J.H. (2000). The complete writings of Joseph H. Pilates. Philadelphia: BainBridgeBooks.

Queiroz, B. C., Cagliari, M. F., Amorim, C. F., \& Sacco, I. C. (2010). Muscle activation during four Pilates core stability exercises in quadruped position. Archives of Physical Medicine and Rehabilitation, 91(1), 86-92.

Rocha-e-Silva, M. (2009). Recent trends in Brazilian medical research. An overview. Clinics (Sao Paulo), 64(10), 1007-1013.

Sacco, I.C.N., Andrade, M.S., Souza, P.S., Nisiyama, M., Cantuária, A.L., Maeda, F.Y.I., \& Pikel, M. (2005). Método Pilates em revista: aspectos biomecânicos de movimentos específicos para reestruturação postural - estudos de caso. Revista Brasileira de Fisiotearpia e Movimento, 13(4), 65-78.

SENIAM. Project 2005. Retrieved 07.agosto.2010, from http://www. seniam.org

Stolze, L., Allison, S. C., \& Childs, J. D. (2012). Derivation of a preliminary clinical prediction rule for identifying a subgroup of patients with low back pain likely to benefit from pilates-based exercise. Journal of Orthopaedic \& Sports Physical Therapy, 42(5), 425-436.

Van Dieen, J. H., Cholewicki, J., \& Radebold, A. (2003). Trunk muscle recruitment patterns in patients with low back pain enhance the stability of the lumbar spine. Spine, 28(8), 834-841.

Wells, C., Kolt, G. S., \& Bialocerkowski, A. (2012). Defining Pilates exercise: a systematic review. Complementary Therapies in $\mathrm{Me}$ dicine, 20(4), 253-262.

Wilke, H. J., Wolf, S., Claes, L. E., Arand, M., \& Wiesend, A. (1995). Stability increase of the lumbar spine with different muscle groups. A biomechanical in vitro study. Spine, 20(2), 192-198.
Wong, K. W., Leong, J. C., Chan, M. K., Luk, K. D., \& Lu, W. W. (2004). The flexion-extension profile of lumbar spine in 100 healthy volunteers. Spine, 29(15), 1636-1641.

\section{Authors' note}

Isabel C.N. Sacco, Eduardo T.T. Mori, Bergson C. Queiroz, and Ivye L. R. Pereira are affiliated with the Physical Therapy, Speech and Occupational Therapy Department, School of Medicine, University of São Paulo, SP, Brazil.

Nadia Marconi is affiliated with the Physical Therapy Department, University of Brasília, DF, Brazil.

\section{Corresponding author:}

Dr. Isabel Sacco

Movement and Posture Biomechanics Laboratory; Physiotherapy, Speech Therapy and Occupational Therapy Department. USP Rua Cipotânea, 51, Cidade Universitária, São Paulo, SP 056360-160, Brazil Phone: 551130918426.

Email: icnsacco@usp.br www.usp.br/labimph.

\section{Acknowledgements}

The authors are grateful to CNPq (National Council for Scientific and Technological Development) for the scholarship awarded to Mori, to Olavo Luppi Silva for supporting the EMG processing, and to Nove de Julho University, where data were collected. There is no commercial relationship, which may lead to a conflict of interests, whether financial or personal, with third parties or persons.

Manuscript received on September 15, 2013

Manuscript accepted on March 19, 2014

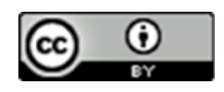

Motriz. The Journal of Physical Education. UNESP. Rio Claro, SP, Brazil - eISSN: 1980-6574 - under a license Creative Commons - Version 3.0 